
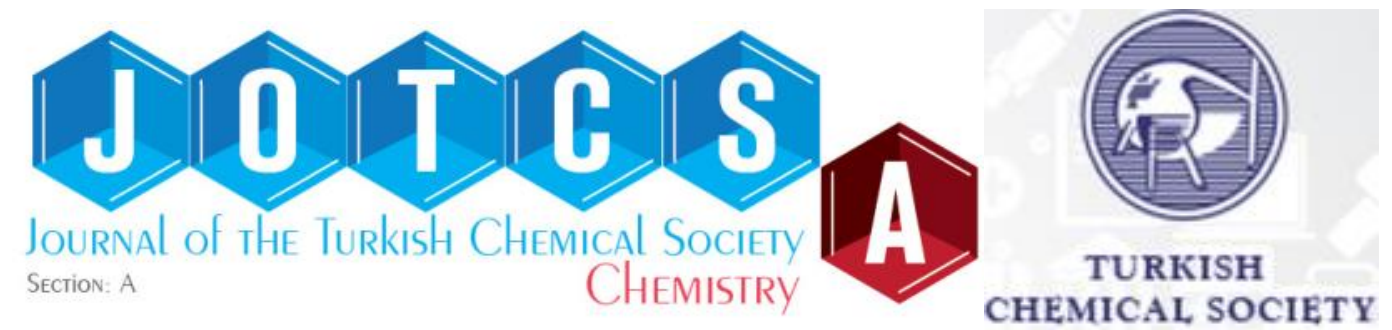

\title{
Structural, Spectroscopic and Activity Calculations on Methanesulfonylhydrazone Derivative Chromium Pentacarbonyl Complexes
}

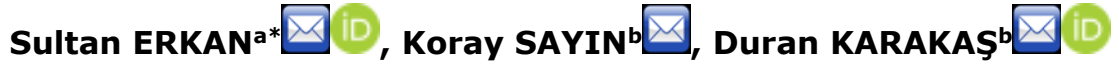 \\ ${ }^{*}$ a Chemistry and Chemical Processing Technologies, Cumhuriyet University Yildizeli Vocational School, \\ 58140 Sivas, Turkey \\ ${ }^{\mathrm{b}}$ Inorganic Chemistry, Faculty of Science, Cumhuriyet University, 58140 Sivas, Turkey
}

Abstract: The thiophene-2-carboxyaldehyde methanesulfonylhydrazone (msh1), 2-acetylthiophene methanesulfonylhydrazone (msh2) and 2-acetyl-5-methylthiophene methanesulfonylhydrazone (msh3) ligands, a heteroatomic methanesulfonylhydrazone derivative, was optimized by using HF and DFT (B3LYP) method with $6-31 \mathrm{G}(\mathrm{d}, \mathrm{p})$ basis set. The calculated IR spectra for msh1, msh2 and msh3 were compared with experimental data and the suitability of the calculation methods was discussed. LANL2DZ and GEN basis sets were used for calculations of chromium pentacarbonyl complexes containing msh1, msh2 and msh3 ligands. According to the experimental IR spectra the most appropriate method and basis set was determined. Structural parameters of ligands and complexes were predicted. To investigate the biological activities of ligands and complexes, some activity descriptors were obtained from optimized structures. Molecular electrostatic potential (MEP) maps of the mentioned ligands and complexes were examined and active sites were determined. The molecular docking study of ligands and complexes with Bacillus cereus (PDB ID $=5 \mathrm{~V} 8 \mathrm{E})$, Staphylococcus aureus (PDB ID $=1 \mathrm{BQB}$ ), and Candida albicans (PDB ID=1AI9) were performed.

Keywords: methanesulfonylhydrazone, chromium pentacarbonyl complexes, computational chemistry, molecular docking.

Submitted: May 30, 2018. Accepted: September 30, 2018.

Cite this: Erkan S, Sayın K, Karakaş D. Structural, Spectroscopic and Activity Calculations on Methanesulfonylhydrazone Derivative Chromium Pentacarbonyl Complexes. JOTCSA. 2018;5(3):1193204.

DOI: $\underline{\text { http://dx.doi.org/10.18596/jotcsa.428788. }}$

*Corresponding author. E-mail: sultanerkan58@gmail.com.

\section{INTRODUCTION}

The pharmacological and chemical interest of the compounds containing the sulfonyl hydrazone moiety is increasing day by day (1). Sulfonamide drugs are used as chemotherapeutic agents because they have a broad spectrum of activity (2). Most compounds containing carboxylic acid hydrazones exhibit cytostatic activity. Sulfonamides $\left(-\mathrm{SO}_{2} \mathrm{NH}-\right)$ are widely used as antimicrobial agents due to their lower cost, lower toxicity and most of their activity against bacterial diseases (3). Methane sulfonamide derivatives have DNA binding ability and show cytostatic effects that are used in cancer chemotherapy.
Hydrazonic compounds have interesting biological properties such as antibacterial (4), antidepressant (5), antiinflammatory, analgesic $(6,7)$ and antipyretic activity $(8)$. Hydrazones are important compounds for drug design with the synthesis of metal complexes, organocatalysis and heteroaromatic compounds (9). Sulfones containing heteroaromatic moieties have been discovered to exhibit interesting antibacterial and antifungal bioactivity. For this reason, the synthesis of sulfones has attracted great interest in pesticides and medical formulations (10). Sulfonylhydrazones derived from sulfonamides have pharmacological properties such as 
antibacterial, anticancer, antiviral, antinociceptive activity, and particularly enzyme inhibition to carbonic anhydrase species (11-14). Most physiologically active hydrazones have applications in the treatment of diseases such as tuberculosis, leprosy and mental damage.

Theoretical studies based on quantum mechanics are used to obtain information on some physical and chemical properties of chemical compounds $(15,16)$. For example, vibration spectroscopy is versatile and an easily available tool to interpret and predict the properties of chemically and biologically active molecules. These theoretical studies have been used in both chemical kinetic and chemical analysis studies $(17,18)$. However, in addition to the labeling of vibration modes, the relationship between the observed spectroscopic properties and the molecular structure may be difficult to understand (19). In recent years, DFT and HF methods have been used to determine the molecular structure and vibration spectra of molecules with low computational cost (20-25). These calculation methods can give systematic errors due to limited basis sets, harmonic approaches and neglect in electron correlations (26).

The thiophene-2-carboxyaldehyde methanesulfonylhydrazone (msh1), 2acetylthiophene methanesulfonylhydrazone (msh2) and 2-acetyl-5-methylthiophene methanesulfonylhydrazone (msh3) which are the heteroatomic methanesulfonylhydrazone derivatives and chromium pentacarbonyl complexes of these ligands were synthesized by G. Orhan et al. in 2014. The synthesized ligands and complexes were examined only in terms of spectroscopy. In this work, msh1, msh2 and msh3 were optimized with $\mathrm{HF} / 6-31 \mathrm{G}(\mathrm{d}, \mathrm{p})$ and B3LYP/6-31G(d,p) level. The experimental data were compared with the calculated IR spectra of msh1, msh2 and msh3. The suitability of the calculation methods according to the correlation coefficients were discussed. The HF and DFT (B3LYP) methods LANL2DZ and GEN (LANL2DZ for metal and $6-31 G(d, p)$ for other atoms) basis sets were used for the calculations of chromium pentacarbonyl complexes are given in Figure 1. The suitability of the levels used for the mentioned complexes was discussed according to the experimental stretching frequencies. Structural parameters of the studied ligands and complexes were predicted.

There were antimicrobial studies for sulfonylhydrazone derivatives in the literature. For example, Gunduzalp et al. examined the antimicrobial activities

of aromatic/heteroaromatic sulfonylhydrazone derivatives in 2014 (27). For this reason, some quantum chemical identifiers such as the highest occupied molecular orbital ( $\mathrm{E}_{\text {номо }}$ ), energy of the lowest unoccupied molecular orbital (ELUMO), energy gap between LUMO and HOMO (E $\mathrm{E}_{\mathrm{GAP}}$ ), absolute hardness $(\eta)$, absolute softness $(\sigma)$, absolute electronegativity $(\mathrm{X})$, chemical potential $(\mu)$, electrophilicity index $(\omega)$, nucleophilicity index $(\varepsilon)$ and global softness (S) were studied to investigate the structure-activity relationship. Molecular electrostatic potential (MEP) maps were examined to determine the active areas of the molecules. Finally, molecular docking studies were done theoretically for some types of bacterial and fungal activities. The lack of experimental biological activity for the ligands and complexes mentioned was theoretically illuminated.

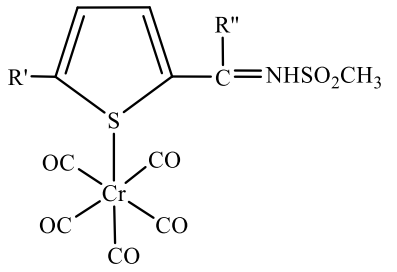

$$
\begin{array}{ll}
\mathrm{msh} 1: \mathrm{R}^{\prime}=\mathrm{H} & \mathrm{R} "=\mathrm{H} \\
\mathrm{msh} 2: \mathrm{R}^{\prime}=\mathrm{H} & \mathrm{R} "=\mathrm{CH}_{3} \\
\mathrm{msh} 3: \mathrm{R}^{\prime}=\mathrm{CH}_{3} & \mathrm{R}=\mathrm{CH}_{3}
\end{array}
$$

Figure 1. Schematic diagram of studied chromium complexes.

\section{Calculation method}

The input files of msh1, msh2 and msh3 ligands and their chromium pentacarbonyl complexes were prepared with GaussView 5.0.8 (28). All calculations were done using Gaussian 09 AML64L-Revision-C.01 (29). The HF (30) and B3LYP (31) methods and 6-31G(d,p) level for optimization of the mentioned ligands and $\mathrm{HF}$ and B3LYP methods and LANL2DZ and GEN levels for optimization of the mentioned complexes were performed in gaseous phase.

B3LYP/6-31G(d,p) for ligands and B3LYP/GEN for complexes were determined to be the optimal level. DFT methods are taken in account of electron exchange and correlation. Basis sets are often used to create molecular orbitals. $6-31 \mathrm{G}(\mathrm{d}$, $p$ ) is a polarized basis set. It states that $p$ functions are added to the hydrogen atom other d-functions are attached to heavy atoms $(32,33)$. The LANL2DZ is a basis set that uses the effective core potential to model metal atoms (34). So this basis set neglects the inner shell electrons in the bond formation. The GEN keyword is determined by the user. The atomic orbitals of the central atom and the groups bound to the central atom are calculated using separate basis set (35). The molecular identifiers required to predict biological activity are obtained by quantum chemical calculations. Some quantum chemical parameters which are energy of the highest occupied molecular orbital ( $\left.\mathrm{E}_{\text {номо }}\right)$, energy of the lowest unoccupied molecular orbital (ELUMO), energy gap between LUMO and HOMO (E $E_{G A P}$, absolute hardness $(\eta)$, absolute softness $(\sigma)$, absolute electronegativity $(X)$, chemical potential $(\mu)$, electrophilicity index $(\omega)$, nucleophilicity index $(\varepsilon)$ and global softness (S), were calculated by using following equation.

According to the Koopmans' theorem, the ionization energies and the electron affinities of the chemical species are related to the energies 
of their frontier orbitals and are calculated using Equations 1 and 2 (36).

$$
\begin{aligned}
& I=-E_{\text {Номо }} \\
& A=-E_{\text {LUMO }}
\end{aligned}
$$

The difference between the energies of HOMO and LUMO is calculated according to Equation (3).

$$
\Delta E=E_{\text {LUMO }}-E_{\text {HOMO }}
$$

The absolute hardness, softness, absolute electronegativity and chemical potential of the molecules are calculated by Equation (4) - (7) according to R. G. Pearson (37).

$$
\begin{aligned}
\chi & =\frac{I+A}{2} \\
\mu & =-\chi \\
\eta & =\frac{I-A}{2} \\
\sigma & =\frac{1}{\eta}
\end{aligned}
$$

R. G. Parr et al. proposed an identifier called electrophilicity index $(\omega)$. The electrophilicity index is calculated using the following equation (38). The nucleophilicity index $(\varepsilon)$ is the inverse of the electrophilicity index (39). The global softness is a function of absolute hardness, as seen in Equation $10(40,41)$.

$$
\begin{aligned}
\omega & =\frac{\mu^{2}}{2 \eta} \\
\varepsilon & =\frac{1}{\omega} \\
S & =\frac{1}{2 \eta}
\end{aligned}
$$

\section{RESULTS AND DISCUSSION}

\section{Optimized structures of ligand and complexes}

Optimized structures of the ligands msh1, msh2 and $\mathrm{msh} 3$ and the $\mathrm{Cr}(\mathrm{CO})_{5} \mathrm{msh} 1, \mathrm{Cr}(\mathrm{CO})_{5} \mathrm{msh} 2$ and $\mathrm{Cr}(\mathrm{CO})_{5} \mathrm{msh} 3$ complexes are given in Figures 2 and 3 . The optimized structures in the figures were obtained at the B3LYP/GEN level for complexes and at the B3LYP/6-31G(d,p) for ligands in gaseous phase.

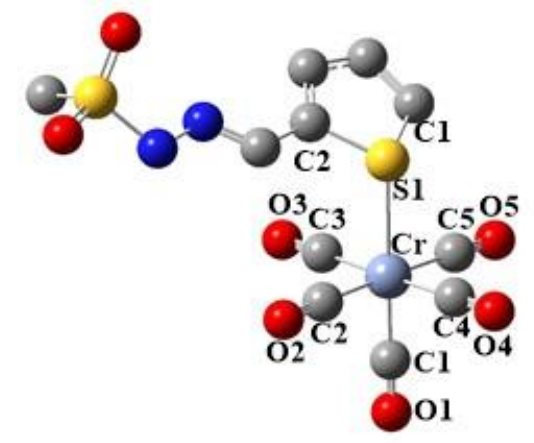

$\mathrm{Cr}(\mathrm{CO})_{5} \mathrm{mshl}$

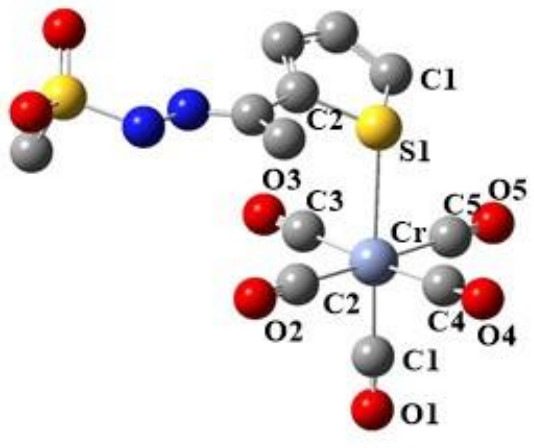

$\mathrm{Cr}(\mathrm{CO})_{5} \mathrm{msh} 2$

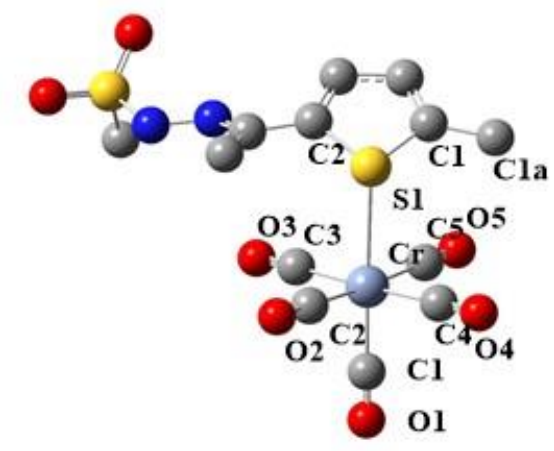

$\mathrm{Cr}(\mathrm{CO})_{5} \mathrm{msh} 3$

Figure 2. The optimized structures of complexes obtained at B3LYP/GEN level. Hydrogen atoms have been removed for aperture.

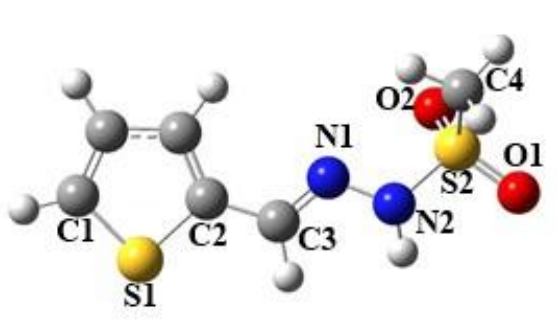

msh1

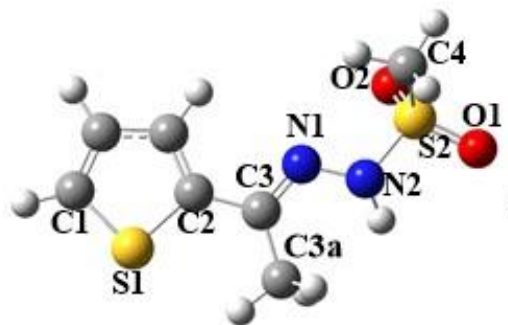

msh2

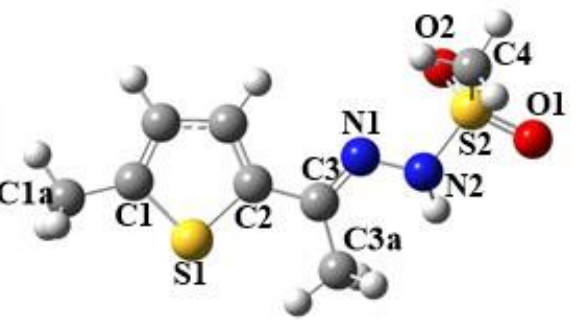

msh3

Figure 3. The optimized structures of ligands obtained at B3LYP/6-31G(d,p) level.

\begin{abstract}
Vibrational Frequencies and Benchmark analysis

Vibrational spectrum is the most important component of molecular structure illumination. Nowadays, the methods computational chemistry provide very useful information in assignment the vibrational spectrum of molecules. However, many methods and basis sets in computational chemistry studies required accurate optimization to be achieved with correct calculation.
\end{abstract}

In this case, the most accurate results, or as mentioned, the most accurate optimization should be that the correlation between the experimental data and the calculated data by using the different methods and the basis set should be investigated. For this reason, Benchmark analysis is an important section of computational studies. The experimental frequencies values of the mentioned ligands and complexes are compared with those of the calculated harmonic frequencies in each level. The distribution graph is plotted by using experimental and computational frequencies for each level and correlation coefficient $(r)$ is calculated from this graph. The experimental vibration spectra and the calculated frequencies with the HF/6-31G(d,p) and DFT/B3LYP/6$31 \mathrm{G}(\mathrm{d}, \mathrm{p})$ level and assignments of frequencies for 
msh1, msh2 and msh3 ligands are given in Table 1.

Table 1. The experimental and calculated IR spectra $\left(\mathrm{v} / \mathrm{cm}^{-1}\right)$ and their assignment for $\mathrm{msh} 1$, msh2 and msh3.

\begin{tabular}{|c|c|c|c|c|c|c|c|c|c|}
\hline & Msh1 & & & Msh2 & & & Msh3 & & \\
\hline HF & B3LYP & EXP. & HF & B3LYP & EXP. & HF & B3LYP & EXP. & ASSIGN. \\
\hline 3745.77 & 3420.14 & 3180 & 3766.77 & 3449.36 & 3226 & 3766.19 & 3448.22 & 3233 & $v \mathrm{NH}$ \\
\hline 3427.79 & 3223.67 & 3090 & 3384.53 & 3222.91 & 3093 & 3375.23 & 3211.86 & 3024 & vCHring \\
\hline 1920.61 & 1678.96 & 1607 & 1911.73 & 1658.68 & 1593 & 1910.35 & 1656.96 & 1598 & $v \mathrm{CN}$ \\
\hline 1470.06 & 1337.5 & 1332 & 1470.32 & 1342.28 & 1331 & 1469.22 & 1341.3 & 1331 & $v\left(\mathrm{SO}_{2}\right)$ asym \\
\hline 1258.62 & 1135.1 & 1158 & 1260.79 & 1137.27 & 1166 & 1259.85 & 1136.56 & 1169 & $v\left(\mathrm{SO}_{2}\right)$ sym \\
\hline 1047.92 & 916.64 & 844 & 1046.56 & 859.51 & 845 & 1030.28 & 964.44 & 923 & vCSCring \\
\hline 891.92 & 817.46 & 770 & 922.34 & 619.44 & 771 & 724.41 & 745.36 & 703 & vCSsym \\
\hline 815.45 & 747.46 & 664 & - & - & - & 804.46 & 684.05 & 583 & vCSasym \\
\hline $0.9951 *$ & $0.9975 *$ & & $0.9937 *$ & $0.9976 *$ & & $0.9944 *$ & $0.9976 *$ & & \\
\hline
\end{tabular}

Table 1 gives the experimental, calculated frequencies for ligands and their labelling. The most appropriate method and basis set were determined according to the correlation coefficients between the calculated and the experimental vibration frequencies. B3LYP/6$31 \mathrm{G}(\mathrm{d}, \mathrm{p})$ was determined as the most appropriate method and basis set because the calculated correlation coefficients $(r)$ were closer to 1 for the three ligands. In addition, for the msh3 ligand, it was experimentally found that symmetric and asymmetric CS stretching bands at 703 and $583 \mathrm{~cm}^{-1}$, respectively, were the opposite in animation.

The carbonyl complexes are optimized with HF and B3LYP methods LANL2DZ and GEN basis sets in gaseous phase. The frequencies obtained from the optimized structures, the experimental stretching frequencies and their labelling are given in Tables 2-4.

Table 2. The harmonic vibration frequencies calculated at HF and B3LYP methods with LANL2DZ and GEN basis sets in gas phase for $\mathrm{Cr}(\mathrm{CO})_{5} \mathrm{msh} 1$

\begin{tabular}{llllll}
\hline HF/LANL2DZ & HF/GEN & B3LYP/LANL2DZ & B3LYP/GEN & EXP. & ASSIGN. \\
\hline 2152.5 & 2317.89 & 2031.15 & 2065.7 & 2060 & vCO \\
2147.34 & 2303.82 & 1931.45 & 2055.46 & 1921 & vCO \\
2118.72 & 2291.25 & 1913.58 & 2046.81 & 1894 & vCO \\
860.42 & 1043.06 & 863.62 & 909.66 & 858 & vCSCring \\
830.77 & 883.79 & 805.48 & 847.46 & 805 & vCSCring \\
654.85 & 650.94 & 732.52 & 804.22 & 650 & vCSsym \\
752.17 & 622.32 & 681.31 & 722.5 & 603 & vCSasym \\
$0.9896 *$ & $0.9927 *$ & $0.9976 *$ & $0.9918 *$ & & \\
sym: symmetric, asym: asymmetric, *the calculated correlation coefficients (r) \\
\hline
\end{tabular}

Table 3. The harmonic vibration frequencies calculated at HF and B3LYP methods with LANL2DZ and GEN basis sets in gas phase for $\mathrm{Cr}(\mathrm{CO}) 5 \mathrm{msh} 2$

\begin{tabular}{|c|c|c|c|c|c|}
\hline HF/LANL2DZ & HF/GEN & B3LYP/LANL2DZ & B3LYP/GEN & EXP. & ASSIGN. \\
\hline 2146.7 & 2317.89 & 2029.61 & 2180.42 & 2060 & $v \mathrm{CO}$ \\
\hline 2132.31 & 2310.66 & 1947.21 & 2053.08 & 1935 & vCO \\
\hline 2126.36 & 2291.25 & 1916.91 & 2049.42 & 1859 & vCO \\
\hline 1426.37 & 1650.35 & 941.31 & 896.74 & 852 & vCSCring \\
\hline 893.91 & 1043.06 & 840.87 & 845.42 & 798 & vCSCring \\
\hline $\begin{array}{l}755.3 \\
670.63 \\
0.9314^{*}\end{array}$ & $\begin{array}{l}883.79 \\
792.53 \\
0.9115^{*}\end{array}$ & $\begin{array}{l}769 \\
680.64 \\
0.9978 *\end{array}$ & $\begin{array}{l}724.99 \\
674.76 \\
0.9979 *\end{array}$ & $\begin{array}{l}655 \\
591\end{array}$ & $\begin{array}{l}\text { vCSsym } \\
\text { vCSasym }\end{array}$ \\
\hline
\end{tabular}


Table 4. The harmonic vibration frequencies calculated at HF and B3LYP methods with LANL2DZ and GEN basis sets in gas phase for $\mathrm{Cr}(\mathrm{CO}) 5 \mathrm{msh} 3$

\begin{tabular}{llllll}
\hline HF/LANL2DZ & HF/GEN & B3LYP/LANL2DZ & B3LYP/GEN & EXP. & ASSIGN. \\
\hline 2255.05 & 2311.66 & 2028.45 & 2151.58 & 2070 & vCO \\
2145.76 & 2305.26 & 1945 & 2056.76 & 1940 & vCO \\
2126.79 & 2298.52 & 1918.64 & 2051.53 & 1889 & vCO \\
1020.89 & 1045.12 & 1169.34 & 1038.87 & 955 & vCSCring \\
785.02 & 792.65 & 1042.42 & 960.81 & 870 & vCSCring \\
679.41 & 713.89 & 932.95 & 724.08 & 618 & vCSsym \\
597.29 & 624.62 & 709.13 & 671 & 577 & vCSasym \\
$0.9934 *$ & $0.9863 *$ & $0.9886 *$ & $0.9986^{*}$ & & \\
sym: symmetric, asym: asymmetric, *the calculated correlation coefficients (r) \\
\hline
\end{tabular}

According to Tables 2-4, B3LYP/GEN level was chosen as the most appropriate method and basis set according to the correlation coefficients of the experimental and calculated vibration frequencies in the charts. When the Tables 2-4 are examined, the experimentally determined carbonyl vibrational frequencies for the $\mathrm{Cr}(\mathrm{CO})_{5} \mathrm{msh} 1$ complex were determined to be 2060, 1935 and $1859 \mathrm{~cm}^{-1}$, these frequencies were calculated as 2065.7, 2055.46 and $2046.81 \mathrm{~cm}^{-1}$, respectively. For other complexes the carbonyl stretching frequencies were also similar. The experimental values were 655 and $591 \mathrm{~cm}^{-1}$ and were labeled as symmetrical and asymmetric CS bond vibrational in the $\mathrm{Cr}(\mathrm{CO})_{5} \mathrm{msh} 2$ complex. But when examined with the animation, it is observed that symmetrical bond tension is asymmetric bond tension and asymmetric bond stretching is symmetrical.

\section{Structural Parameters}

The bond lengths and ligand angles, which are geometric structure parameters calculated at the gas phase at the B3LYP/6-31G(d,p) level of the three mentioned ligands, are given in Table 5.

Table 5. Calculated bond lengths $(\AA)$ and bond angles $\left(^{\circ}\right)$ at the gas phase for B3LYP/6-31G(d, p) for the $\mathrm{msh} 1, \mathrm{msh} 2$ and $\mathrm{msh} 3$.

\begin{tabular}{llll}
\hline Bonds & msh1 & msh2 & msh3 \\
\hline S1-C1 & 1.730 & 1.730 & 1.745 \\
S1-C2 & 1.751 & 1.754 & 1.757 \\
C2-C3 & 1.452 & 1.466 & 1.465 \\
C3-N1 & 1.285 & 1.292 & 1.292 \\
N1-N2 & 1.374 & 1.377 & 1.378 \\
N2-S2 & 1.722 & 1.723 & 1.722 \\
S2-O1 & 1.464 & 1.465 & 1.465 \\
S2-O2 & 1.462 & 1.462 & 1.462 \\
S2-C4 & 1.796 & 1.796 & 1.796 \\
\hline Angles & & & \\
\hline C1-S1-C2 & 91.59 & 91.80 & 92.30 \\
C2-C3-N1 & 121.27 & 116.09 & 116.18 \\
C3-N1-N2 & 117.36 & 118.06 & 117.98 \\
N1-N2-S2 & 114.93 & 114.12 & 114.04 \\
O1-S2-O2 & 121.16 & 121.02 & 120.95 \\
\hline
\end{tabular}

When the bond lengths and bond angles of the ligands are examined, it can be seen that the bond lengths of the S1-C1, C2-C3, C3-N1, N1-N2, $\mathrm{N} 2-\mathrm{S} 2$ and $\mathrm{S}-\mathrm{O}$ bonds are very close to each ligand. It is seen that $\mathrm{C} 1-\mathrm{S} 1-\mathrm{C} 2$ angle is $90^{\circ}$ and C2-C3-N1 angle is about $120^{\circ}$ in the msh1 and about $115^{\circ}$ in the msh2 and msh3. A decrease in the angle due to the presence of methyl groups in $\mathrm{msh} 2$ and msh3 is expected.

The calculated geometric structure parameters in gas phase with the B3LYP/GEN level of $\mathrm{Cr}(\mathrm{CO})_{5} \mathrm{msh} 1, \mathrm{Cr}(\mathrm{CO})_{5} \mathrm{msh} 2$ and $\mathrm{Cr}(\mathrm{CO})_{5} \mathrm{msh} 3$ complexes are given in Table 6 . In the literature, the terminal C-O bond lengths is about $1.15 \AA$. This value was calculated at the B3LYP/GEN level for $\mathrm{C}-\mathrm{O}$ bonds. The fact that the $\mathrm{Cr}-\mathrm{S}$ bond length is numerically larger than the $\mathrm{Cr}-\mathrm{C}$ bond length is due to the large diameter of the sulfide. The angle between chromium and the surrounding carbonyl and methylsulfonylhydrazone ligands is about $90^{\circ}$, indicating that the chromium complex has octahedral geometry. It is also evident that the angle between the $\mathrm{C} 1-\mathrm{S} 1-\mathrm{C} 2$ atoms of the methylsulfonylhydrazone ligand has not changed. 
Table 6. The bond lengths $(\AA)$ and bond angles $\left(^{\circ}\right)$ calculated in gas phase with B3LYP/GEN level for

\begin{tabular}{|c|c|c|c|}
\hline Bonds & $\mathrm{Cr}(\mathrm{CO})_{5} \mathrm{msh1}$ & $\mathrm{Cr}(\mathrm{CO})_{5} \mathrm{msh} 2$ & $\mathrm{Cr}(\mathrm{CO})_{5} \mathrm{msh} 3$ \\
\hline $\mathrm{Cr}-\mathrm{C} 1$ & 1.855 & 1.854 & 1.856 \\
\hline $\mathrm{Cr}-\mathrm{C} 2$ & 1.904 & 1.909 & 1.907 \\
\hline $\mathrm{Cr}-\mathrm{C} 3$ & 1.914 & 1.906 & 1.909 \\
\hline $\mathrm{Cr}-\mathrm{C} 4$ & 1.911 & 1.909 & 1.908 \\
\hline $\mathrm{Cr}-\mathrm{C} 5$ & 1.910 & 1.915 & 1.912 \\
\hline $\mathrm{Cr}-\mathrm{S} 1$ & 2.564 & 2.570 & 2.574 \\
\hline $\mathrm{S} 1-\mathrm{C} 1$ & 1.746 & 1.747 & 1.767 \\
\hline $\mathrm{S} 1-\mathrm{C} 2$ & 1.767 & 1.769 & 1.772 \\
\hline $\mathrm{C} 1-\mathrm{O} 1$ & 1.156 & 1.156 & 1.156 \\
\hline $\mathrm{C} 2-\mathrm{O} 2$ & 1.154 & 1.152 & 1.153 \\
\hline C3-O3 & 1.151 & 1.156 & 1.153 \\
\hline C4-O4 & 1.151 & 1.153 & 1.152 \\
\hline C5-O5 & 1.153 & 1.151 & 1.152 \\
\hline \multicolumn{4}{|l|}{ Angles } \\
\hline $\mathrm{C} 1-\mathrm{Cr}-\mathrm{C} 2$ & 89.1 & 90.4 & 90.2 \\
\hline $\mathrm{C} 1-\mathrm{Cr}-\mathrm{C} 3$ & 90.7 & 89.2 & 89.2 \\
\hline $\mathrm{C} 1-\mathrm{Cr}-\mathrm{C} 4$ & 90.4 & 89.3 & 89.1 \\
\hline $\mathrm{C} 1-\mathrm{Cr}-\mathrm{C} 5$ & 89.2 & 90.7 & 90.4 \\
\hline $\mathrm{C} 1-\mathrm{Cr}-\mathrm{S}$ & 179.1 & 177.4 & 178.1 \\
\hline $\mathrm{C} 2-\mathrm{Cr}-\mathrm{C} 3$ & 90.4 & 90.0 & 90.1 \\
\hline $\mathrm{C} 2-\mathrm{Cr}-\mathrm{C} 4$ & 89.6 & 90.3 & 89.5 \\
\hline $\mathrm{C} 2-\mathrm{Cr}-\mathrm{C} 5$ & 178.3 & 178.7 & 179.3 \\
\hline $\mathrm{C} 2-\mathrm{Cr}-\mathrm{S}$ & 91.4 & 88.7 & 89.1 \\
\hline $\mathrm{C} 3-\mathrm{Cr}-\mathrm{C} 4$ & 178.8 & 178.5 & 178.3 \\
\hline $\mathrm{C} 3-\mathrm{Cr}-\mathrm{C} 5$ & 90.0 & 89.5 & 89.7 \\
\hline C3-Cr-S & 89.9 & 93.2 & 92.5 \\
\hline $\mathrm{C} 4-\mathrm{Cr}-\mathrm{C} 5$ & 89.9 & 89.5 & 90.7 \\
\hline $\mathrm{C} 4-\mathrm{Cr}-\mathrm{S}$ & 88.9 & 90.1 & 89.1 \\
\hline $\mathrm{C} 5-\mathrm{Cr}-\mathrm{S}$ & 90.2 & 90.1 & 90.3 \\
\hline $\mathrm{C} 1-\mathrm{S}-\mathrm{C} 2$ & 91.6 & 91.7 & 92.3 \\
\hline
\end{tabular}

\section{The Activity Studies with Quantum Chemical Descriptor}

Some quantum chemical parameters obtained from optimized molecular structures are useful for predicting biological activity. In many recent studies, there is a unique relationship between calculated quantum chemical parameters and experimental inhibition activities. Since HOMO is the highest energy orbital containing electrons, it acts as an electron donor orbital. If $\mathrm{E}_{\text {номо }}$ increases, the inhibitor electron emission is facilitated and the inhibition activity is increased. Similarly, if the E Eumo energy is low, the ability of the inhibitor to interact increases and this means an increase in inhibitory activity. Absolute electronegativity $(X)$ is a chemical identifier that is considered in the comparison of inhibitory activities of chemical species. Inhibitors with low electronegativity values have easy electron donating ability and thus show high inhibition activity. The chemical potential $(\mu)$ is exactly the opposite of electronegativity. For this reason, the inhibition activity is increased by the increase of the chemical potential. The electrophilicity index $(\omega)$ is a numerical representation of a molecule's global electrophilic force. The electrophilicity index represents chemical reactivity and is a measure of the ability to receive electrons. These indexes were presented in the calculation method section. According to them, biological reactivity increases with increasing of nucleophilicity index $(\varepsilon)$ and decreasing of electrophilicity index. The increasing of the value of global softness implies that biological activity of the compound is the increasing. In this light, these parameters examined for the mentioned molecules are given in Table 7. 
Table 7. The calculated quantum chemical descriptors of the studied molecules.

\begin{tabular}{|c|c|c|c|c|c|c|}
\hline & msh1 & msh2 & msh3 & $\mathrm{Cr}(\mathrm{CO})_{5}(\mathrm{msh} 1)$ & $\mathrm{Cr}(\mathrm{CO})_{5}(\mathrm{msh} 2)$ & $\mathrm{Cr}(\mathrm{CO})_{5}(\mathrm{msh} 3)$ \\
\hline $\mathrm{E}_{\text {Hомо }} *$ & -1.6504 & -1.4664 & -1.3883 & -6.4032 & -6.3602 & -6.2589 \\
\hline ELUMO $*$ & -6.0769 & -5.9602 & -5.7672 & -2.4469 & -2.2983 & -2.2289 \\
\hline$\Delta \mathrm{E}^{*}$ & -4.4265 & -4.4937 & -4.3789 & 3.9563 & 4.0619 & 4.0300 \\
\hline$\eta^{*}$ & -2.2133 & -2.2469 & -2.1894 & 1.9781 & 2.0309 & 2.0150 \\
\hline$\sigma^{* *}$ & -0.4518 & -0.4451 & -0.4567 & 0.5055 & 0.4924 & 0.4963 \\
\hline$\chi^{*}$ & 3.8636 & 3.7133 & 3.5778 & 4.4250 & 4.3292 & 4.2439 \\
\hline$\mu^{*}$ & -3.8636 & -3.7133 & -3.5778 & -4.4250 & -4.3292 & -4.2439 \\
\hline$\omega^{*}$ & -3.3723 & -3.0684 & -2.9232 & 4.9493 & 4.6142 & 4.4692 \\
\hline$\varepsilon^{* *}$ & -0.2965 & -0.3259 & -0.3421 & 0.2021 & 0.2167 & 0.2238 \\
\hline $\mathrm{S} * *$ & -0.2259 & -0.2225 & -0.2284 & 0.2528 & 0.2462 & 0.2481 \\
\hline
\end{tabular}

According to Table 7, the order of activity of the investigated compounds according to the respective parameters is as follows:

According to $\mathbf{E}_{\text {номо, }} \chi, \mu, \omega$ and $\varepsilon: \operatorname{msh} 3>\mathrm{msh} 2$ $>\operatorname{msh} 1$

$$
\begin{gathered}
\mathrm{Cr}(\mathrm{CO})_{5}(\mathrm{msh} 3)>\mathrm{Cr}(\mathrm{CO})_{5}(\mathrm{msh} 2)> \\
\mathrm{Cr}(\mathrm{CO})_{5}(\mathrm{msh} 1)
\end{gathered}
$$

According to $\mathbf{E}_{\text {Lumo: }}$ msh1 $>$ msh2 $>$ msh3

$$
\mathrm{Cr}(\mathrm{CO})_{5}(\mathrm{msh} 1)>\mathrm{Cr}(\mathrm{CO})_{5}(\mathrm{msh} 2)>
$$

$$
\mathrm{Cr}(\mathrm{CO})_{5}(\mathrm{msh} 3)
$$

According to $\Delta \mathbf{E}, \mathbf{\eta}, \boldsymbol{\sigma}$ and $\mathbf{S}: \mathrm{msh} 2>\mathrm{msh} 1>$ msh3

$$
\begin{gathered}
\mathrm{Cr}(\mathrm{CO})_{5}(\mathrm{msh} 1)>\mathrm{Cr}(\mathrm{CO})_{5}(\mathrm{msh} 3)> \\
\mathrm{Cr}(\mathrm{CO})_{5}(\mathrm{msh} 2)
\end{gathered}
$$

\section{Molecular electrostatic potential (MEP)} maps
Molecular electrostatic potential (MEP) maps show electrostatic regions within the molecule. MEP maps define the region of high electron density in red and low electron density in blue color. This is important in determining the electrostatic attack on the red zone and the nucleophilic attack on the blue zone. MEP maps obtained with computational chemistry methods provide useful information even in drug design. For example, it is important to know where to bind the species to be inhibited by the molecule synthesized as the drug (42-45). The MEP maps calculated for the investigated ligands and complexes were shown in Figures 4 and 5, respectively.

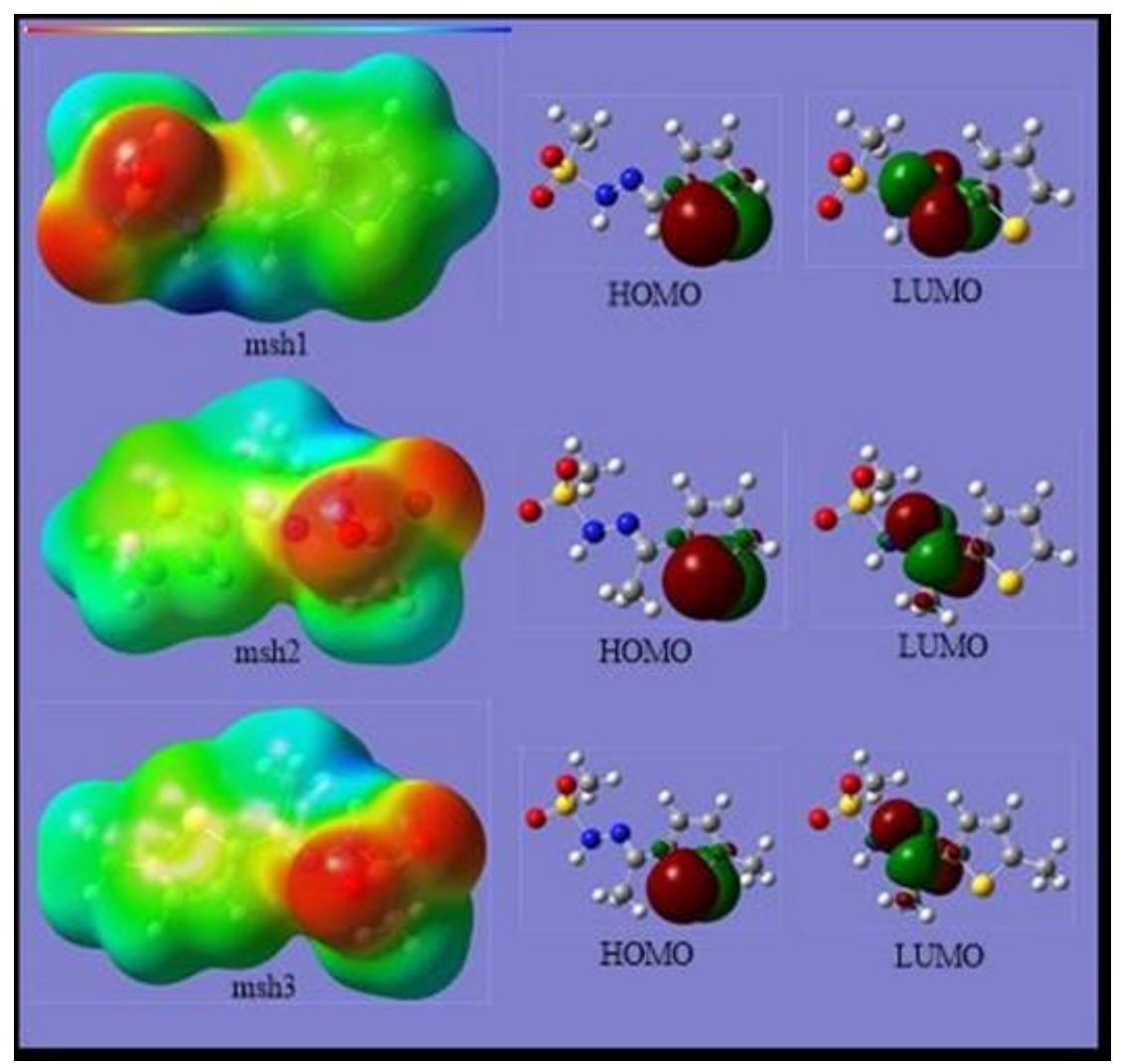

Figure 4. MEP maps and contour diagrams of mentioned ligands. 


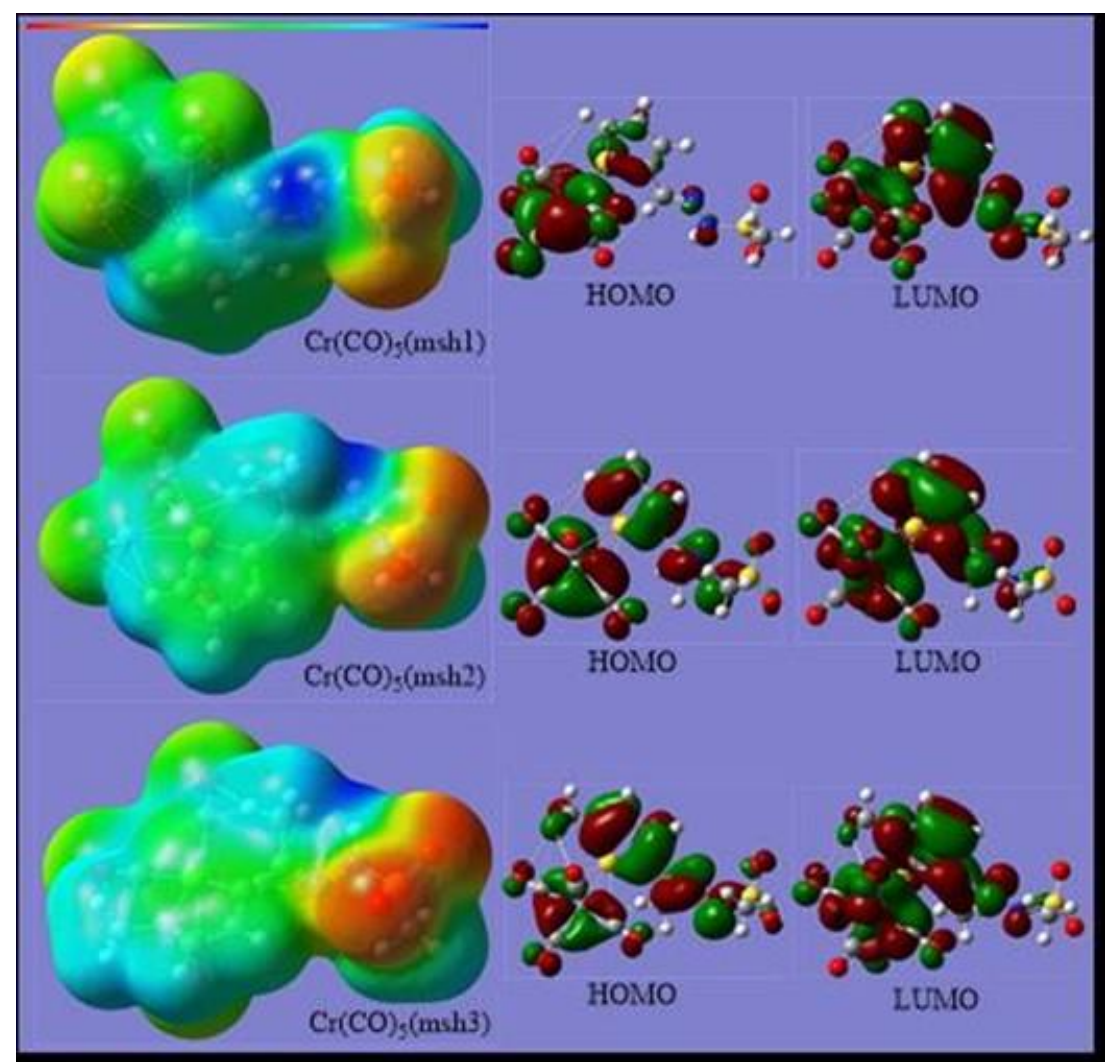

Figure 5. MEP maps and contour diagrams of mentioned complexes.

When MEP maps are examined, active sites in the ligands and complexes are usually regions where oxygen atoms are present. It can be considered as electrophilic sites in regions where oxygen atoms are present. The frontier molecular orbitals, the highest occupied molecular orbital (HOMO) and the lowest unoccupied molecular orbital (LUMO) are associated with spectral properties and activities of the compounds.

\section{Molecular Docking}

As is known, molecular docking studies support experimental antimicrobial studies. The antimicrobial effects of many sulfonylhydrazone derivatives have been experimentally investigated. Antimicrobial efficiency is not included in the literature for the mentioned ligands and complexes. For this reason, molecular docking studies for ligands and complexes against some bacterial and fungal cells that were studied experimentally were performed with the HEX8 program. The binding energies between Bacillus cereus (PDB ID:5V8E) (46), Staphylococcus aureus (PDB ID:1BQB) (47) and Candida albicans (PDB ID:1AI9) (48) and the studied ligands and complexes were investigated and these binding energies are listed in Table 8 . Forms of active binding with target proteins for the studied ligands and complexes were given in Figures 6 and 7 , respectively.

Table 8. The binding energies $(\mathrm{kJ} / \mathrm{mol})$ between the msh1-3 and $\mathrm{Cr}(\mathrm{CO})_{5}(\mathrm{msh} 1)-\mathrm{Cr}(\mathrm{CO})_{5}(\mathrm{msh} 3)$ with the target proteins.

\begin{tabular}{|c|c|c|c|}
\hline & 5V8E & 1BQB & 1 AI9 \\
\hline Msh1 & -198.60 & -201.70 & -194.55 \\
\hline Msh2 & -193.22 & -196.42 & -192.82 \\
\hline Msh3 & -202.88 & -214.96 & -204.51 \\
\hline $\mathrm{Cr}(\mathrm{CO})_{5}(\mathrm{msh} 1)$ & -511.18 & -494.93 & -318.60 \\
\hline $\mathrm{Cr}(\mathrm{CO})_{5}(\mathrm{msh} 2)$ & -409.79 & -473.45 & -321.82 \\
\hline $\mathrm{Cr}(\mathrm{CO})_{5}(\mathrm{msh} 3)$ & -487.06 & -465.73 & -325.02 \\
\hline
\end{tabular}


mshl to 5V8E

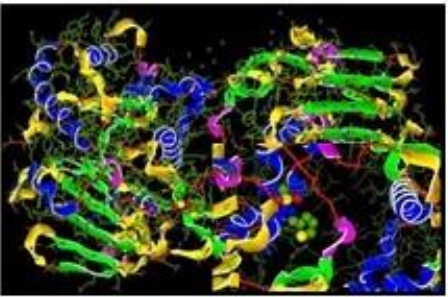

mshl to $1 B Q B$

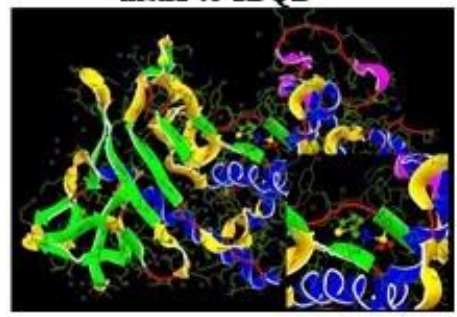

mshl to 1AI9

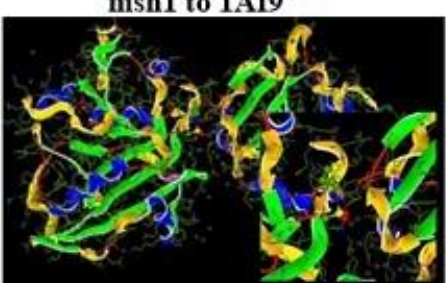

msh2 to 5V8E

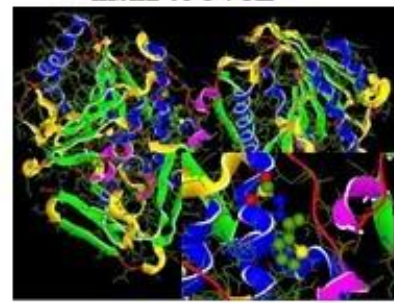

msh2 to 1BQB

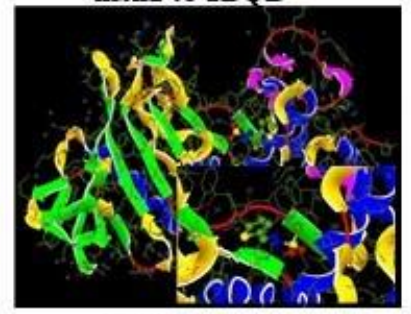

$\mathrm{msh} 2$ to $1 \mathrm{AI} 9$

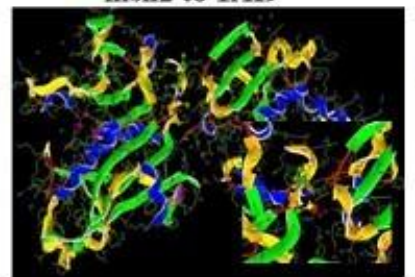

$\mathrm{msh} 3$ to $5 \mathrm{~V} 8 \mathrm{E}$

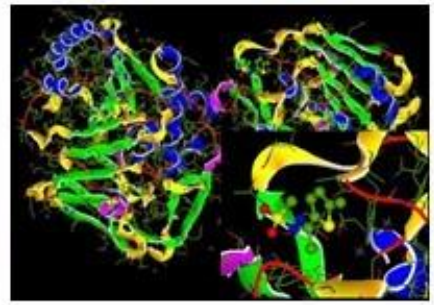

msh3 to $1 B Q B$

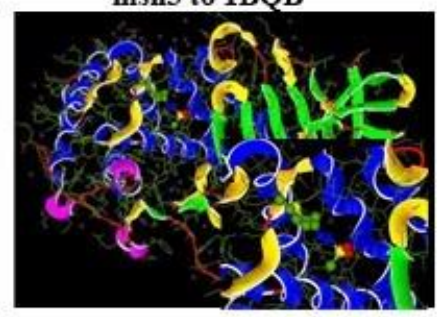

msh3 to 1 AI9

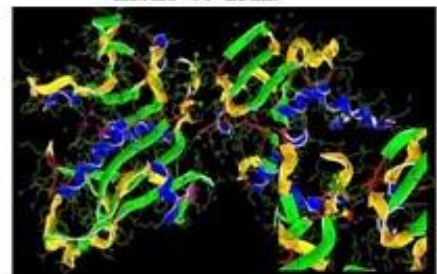

Figure 6. The binding region between the mentioned ligands with the target proteins.

Comp.1 to 5V8E

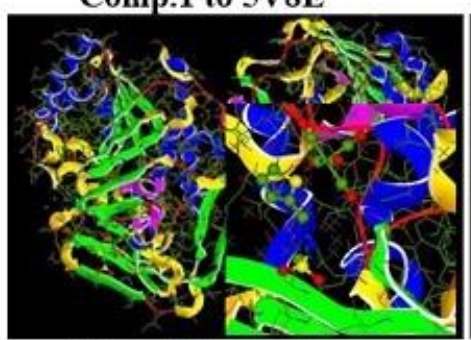

Comp.1 to $1 \mathrm{BQB}$

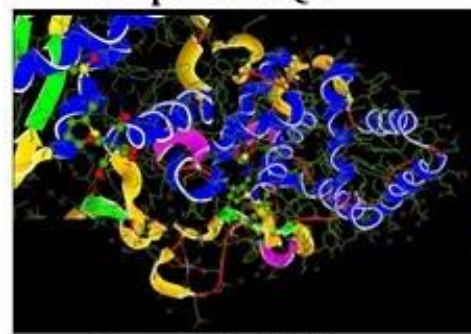

Comp.1 to 1AI9

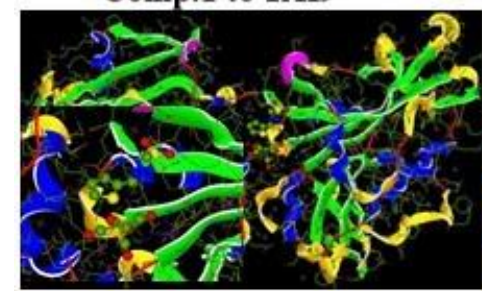

Comp.2 to 5 V8E

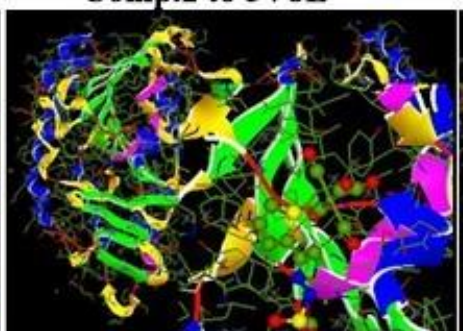

Comp.2 to 1BQB

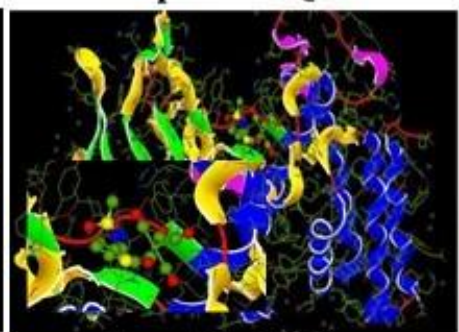

Comp.2 to 1AI9

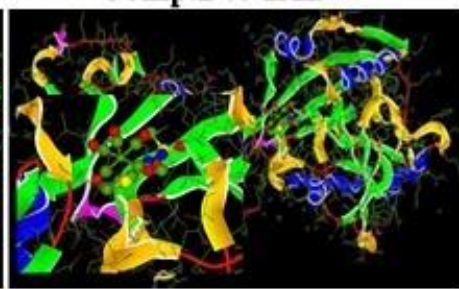

Comp.3 to 5 V8E

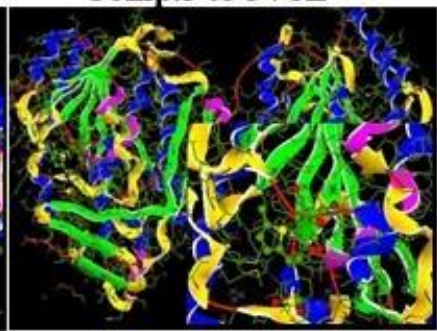

Comp.3 to 1BQB

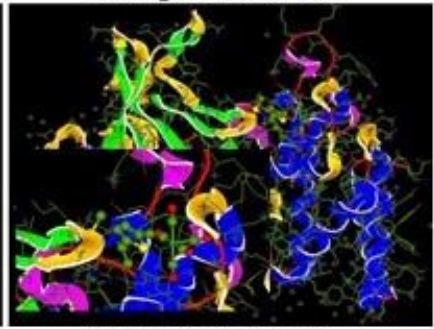

Comp.3 to 1AI9

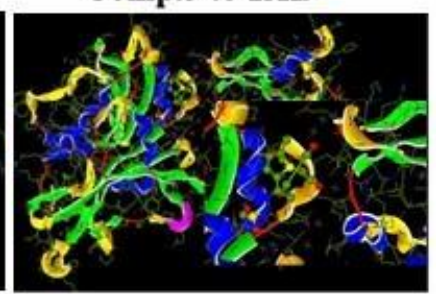

Figure 7. The binding region between the mentioned complexes with the target proteins.

When the binding energies are examined, it is that seen the cobalt carbonyl complexes of methylsulfonylhydrazone derivatives are more advantageous in terms of antimicrobial effectiveness. According to the binding energies of the ligands with the target proteins, msh3 has the highest antimicrobial activity. However, in complexes, $\mathrm{Co}(\mathrm{CO})_{5} \mathrm{msh} 1$ has the highest binding energy value with all target proteins.

\section{CONCLUSIONS}

IR spectra calculated with HF and DFT (B3LYP) methods were labeled for msh1, msh2 and msh3 ligands and $\mathrm{Co}(\mathrm{CO})_{5} \mathrm{msh} 1, \mathrm{Co}(\mathrm{CO})_{5} \mathrm{msh} 2$ and 
$\mathrm{Co}(\mathrm{CO})_{5} \mathrm{msh} 3$ complexes according to experimental frequencies. According to the correlation coefficients, the most appropriate method is DFT(B3LYP) method. The most appropriate results were obtained at the B3LYP/6$31 G(d, p)$ level for ligands, at the B3LYP/GEN level for the complexes. Structural parameters of these ligands and complexes were studied and were predicted about geometrical structures. The biological activity sequences of ligands and complexes were predicted with some quantum chemical identifiers. As a result, the biological activity order of the ligands and complexes according to $\Delta \mathrm{E}, \mathrm{\eta}, \sigma$ and $\mathrm{S}$ values is msh2 > $\operatorname{msh} 1>\operatorname{msh} 3$ and $\operatorname{Cr}(\mathrm{CO})_{5}(\mathrm{msh} 1)>$ $\mathrm{Cr}(\mathrm{CO})_{5}(\mathrm{msh} 3)>\mathrm{Cr}(\mathrm{CO})_{5}(\mathrm{msh} 2)$, respectively. In the MEP maps, the electrophilic sites of the ligands and complexes were appointed as the region of oxygen atoms. Finally, molecular docking calculations are performed between mentioned ligands complexes and proteins. Msh3 in ligands and $\mathrm{Cr}(\mathrm{CO})_{5}(\mathrm{msh} 1)$ in complexes is generally found the best complex in protection from cancer. The binding energies for msh3 with $5 \mathrm{~V} 8 \mathrm{E}, 1 \mathrm{BQB}$ and $1 \mathrm{AI} 9$ are $-202.88,-214.96$ and $204.51 \mathrm{~kJ} / \mathrm{mol}$, respectively. The binding energies for $\mathrm{Cr}(\mathrm{CO})_{5}(\mathrm{msh} 1)$ with $5 \mathrm{~V} 8 \mathrm{E}, 1 \mathrm{BQB}$ and $1 \mathrm{AI} 9$ are $-511.18,-494.93$ and $-318.60 \mathrm{~kJ} / \mathrm{mol}$, respectively.

\section{REFERENCES}

1. Albert A, Selective Toxicity, first ed., Chapman and Hall, London, 1985; 24.

2. Shyam K, Penketh PG, Divo AA, Loomis RH, Patton CL, Sartorelli AC. Synthesis and Evaluation of 1,2,2-Tris(sulfonyl)hydrazines as Antineoplastic and Trypanocidal Agents. J. Med. Chem. 1990; 33: 2259.

3. Özçelik S, Dinçer M, Şekerci M, Balaban A, Özdemir U. NPhenyl-N-(2-

thienylmethylene)hydrazine. Acta Crystallogr Sect. E 2004; 60: 1552-3.

4. Özdemir ÖU, Güvenc P, Sahin E, Hamurcu F. Synthesis, characterization and antibacterial activity of new sulfonamide derivatives and their nickel(II), cobalt(II) complexes. Inorg.Chim. Acta 2009; 362: 2613-8.

5. Kalluraya B, Isloor AM, Frank PV, Jagadeesha RL. Synthesis and pharmacological activity of some-4-(substituted)-2-4-arylhydrazono-3methyl-5- oxo-2-pyrazolin-1-yl] thiazoles. Ind. J. Het. Chem. 2004; 13: 245-8.

6. Oliveira KN, Costa P, Santin JR, Mazzambani L, Bürger C, Mora C, Nunes RJ. Synthesis and antidepressant-like activity evaluation of sulphonamides and sulphonyl-hydrazones. Bioorg. Med. Chem. 2011; 19: 4295-306.
7. Sondhi SM, Dinodia M, Kumar A. Synthesis, anti-inflammatory and hydrazine derivatives, Bioorg. Med. Chem. 2006; 14: 4657-63.

8. Raynaud FI, Parker P, Workman P, Waterfield MD. Synthesis and biological evaluation of sulfonylhydrazone-substituted imidazo[1,2a]pyridines as novel PI3 kinase p110alpha inhibitors. Bioorg. Med. Chem. 2007; 15: 583744.

9. Hamurcu F, Mamas S, Ozdemir UO, Gündüzalp $A B$, Senturk OS. New series of aromatic/ five-membered heteroaromatic butanesulfonyl hydrazones as potent biological agents: Synthesis, physicochemical and electronic properties. Journal of Molecular Structure 2016; 1118: 18-27.

10. Mahajan NS, Jadhav RL, Pimpodkar NV, Dias RJ, Manikrao AM. Green Solid Oxidation of Sulfides to Sulfones Using Oxone and Biological Evaluation, Asian J. Chem. 2009; 21: 5415-20.

11. Ozdemir UO, Olgun G, Synthesis, characterization and antibacterial activity of new sulfonyl hydrazone derivatives and their nickel(II) complexes. Spectrochim. Acta Part A 2008; 70: 641-5.

12. Ozdemir UO, Akkaya N, Ozbek N. New nickel(II), palladium(II), platinum(II) complexes with aromatic methanesulfonylhydrazone based ligands, Synthesis, spectroscopic characterization and in vitro antibacterial evaluation. Inorg. Chim. Acta 2013; 400: 13-9.

13. Ozdemir UO, Arslan F, Hamurcu F. Synthesis, characterization, antibacterial activities and carbonic anhydrase enzyme inhibitor effects of new arylsulfonylhydrazone and their Ni(II), Co(II) complexes. Spectrochim. Acta Part A 2010; 75: 121-6.

14. Ozdemir UO, Altuntas $A$, Gündüzalp $A B$, Arslan F, Hamurcu F. New aromatic/heteroaromatic propanesulfonylhydrazone compounds: Synthesis, physical properties and inhibition studies against carbonic anhydrase II(CAII) enzyme. Spectrochim. Acta Part A 2014; 128: 452-60.

15. Chermette $H$. Density functional theory: A powerful tool for theoretical studies in coordination chemistry. Coord. Chem. Rev. 1998;178-180: 699-721.

16. Corminboeuf C, Tran F, Weber J. The role of density functional theory in chemistry: Some historical landmarks and applications to zeolites. J. Mol. Struct: THEOCHEM 2006; 672: 1-7.

17. Kart SÖ, Tanbog AE, Soyleyici HC, Ak M, Kart $\mathrm{HH}$. Theoretical study of the structureproperties relationship in new class of 2,5-di(2- 
thienyl)pyrrole compounds. Spectrochimica Acta Part A: Molecular and Biomolecular Spectroscopy 2015; 137: 1174-83.

18. Krishnakumar $\mathrm{V}$, Xavier RJ, Chithambarathanu T. Ab initio/DFT calculations of butyl ammonium salt of $\mathrm{O}, \mathrm{O}^{\prime}$-dibornyl dithiophosphate. Spectrochimica Acta Part A: Molecular and Biomolecular Spectroscopy 2014; 129: 421-8.

19. Karabacak M, Sahin E, Cinar M, Erol I, Kurt M. X-ray, FT-Raman, FT-IR spectra and ab initio HF, DFT calculations of 2-[(5-methylisoxazol-3yl)amino]-2-oxo-ethyl methacrylate. J. Mol. Struct. 2008; 886: 148-57.

20. Sayin K, Karakaş D, Erkan SK, Sayin TA. Computational study of some fluoroquinolones: Structural, spectral and docking investigations. Journal of Molecular Structure, 2018; 1156: 172-81.

21. Erkan SK, Sayin K, Karakaş D. Theoretical study on the antitumor properties of Ru (II) complexes containing 2-pyridyl, 2-pyridine-4carboxylic acid ligands. Journal of Molecular Structure, 2017; 1149: 473-86.

22. Erkan SK. Spectroscopic and Quantum Chemical Studies on Some $\beta$-Lactam Inhibitors. Turkish Computational and Theoretical Chemistry, 2017; 1.2: 13-26.

23. Sarigul M, Erkan S K, Deveci P, Atabey $H$, Karakas D, Kurtoglu M. Multi-properties of a new azo-Schiff base and its binuclear copper (II) chelate: Preparation, spectral characterization, electrochemical, potentiometric and modeling studies. Journal of Molecular Structure 2017; 1149: 520-9.

24. Gungor SA, Sahin I, Gungor O, Erkan SK, Tumer F, Kose M. Pamoic acid esters and their xanthene derivatives: Flourimetric detection of nitroaromatic compounds and non-linear optical properties. Sensors and Actuators B: Chemical 2018; 255: 3344-54.

25. Karakaş D, Erkan SK. Theoretical investigation on the vibrational and electronic spectra of three isomeric forms of dicobalt octacarbonyl. Journal of Molecular Structure 2014; 1062: 77-81.

26. Katsyuba S, Vandyukova E. Scaled quantum mechanical computations of vibrational spectra of organoelement molecules, containing the atoms $\mathrm{P}, \mathrm{S}$, and $\mathrm{Cl}$. Chem. Phys. Lett. 2003; 377: 658-62.

27. Dennington II RD, Keith TA, Millam JM. GaussView 5.0, Wallingford, CT, 2009.

28. Balaban Gunduzalp A, Ozdemir Ozmen U, Cevrimli BS, Mamas S, Cete S. Synthesis, characterization, electrochemical behavior, and antimicrobial activities of aromatic/heteroaromatic sulfonylhydrazone derivatives. Med Chem Res 2014; 23: 3255-68.

29. Frisch MJ, Trucks GW, Schlegel HB, Scuseria GE, Robb MA, Cheeseman JR, Scalmani G, Barone V, Mennucci B, Petersson GA, Nakatsuji $H$, Caricato $M$, Li X, Hratchian HP, Izmaylov AF, Bloino J, Zheng G, Sonnenberg JL, Hada M, Ehara M, Toyota K, Fukuda R, Hasegawa J, Ishida M, Nakajima T, Honda $Y$, Kitao O, Nakai $\mathrm{H}$, Vreven $\mathrm{T}$, Montgomery Jr JA, Peralta JE, Ogliaro F, Bearpark M, Heyd JJ, Brothers E, Kudin KN, Staroverov VN, Kobayashi R, Normand J, Raghavachari K, Rendell A, Burant JC, Iyengar SS, Tomasi J, Cossi M, Rega N, Millam JM, Klene M, Knox JE, Cross JB, Bakken V, Adamo C, Jaramillo J, Gomperts R, Stratmann RE, Yazyev O, Austin AJ, Cammi R, Pomelli C, Ochterski JW, Martin RL, Morokuma K, Zakrzewski VG, Voth GA, Salvador $P$, Dannenberg J], Dapprich S, Daniels AD, Farkas O, Foresman JB, Ortiz JV, Cioslowski J, Fox DJ, Gaussian, Inc., Wallingford CT, 2009.

30. Pople JA, Raghavachari K, Schlegel HB, Binkley JS, Derivative Studies in Hartree-Fock and Møller-Plesset Theories, Int. J. Quantum Chem., Quant. Chem. Symp., 1979; S13: 22541.

31. Frisch MJ, Trucks GW, Schlegel HB, Gill PMW, Johnson BG, Wong MW, Foresman JB, Robb MA, Head-Gordon M, Replogle ES, Gomperts R, Andres JL, Raghavachari K, Binkley JS, Gonzalez C, Martin RL, Fox DJ, Defrees DJ, Baker J, Stewart JJP, Pople JA, Gaussian 92/DFT(Gaussian, Inc., Pittsburgh, PA, 1993.

32. Frisch MJ, Pople JA, Binkley JS, SelfConsistent Molecular Orbital Methods 25: Supplementary Functions for Gaussian Basis Sets, J. Chem. Phys. 1984; 80: 3265-9.

33. Foresman JB, Frisch E, Exploring Chemistry with Electronic Structure Methods, Gaussian. 2010

34. Dunning $\mathrm{TH}$, Hay Jr, Hay PJ, in Modern Theoretical Chemistry, Ed. H. F. Schaefer, III, Plenum: New York, 1976, 1-28.

35.

http://www.uam.es/departamentos/ciencias/qui mica/estruct/Manuales/Gaussian98/00000439.ht $\mathrm{m}$

36. Pearson, Ralph G. Recent advances in the concept of hard and soft acids and bases. Journal of Chemical Education, 1987, 64.7: 561.

37. Pearson RG, Inorg. Chem., 1988; 27: 73440 
38. Parr RG, Yang W, Density-functional Theory of Atoms and Molecules Oxford Univ. Press, New-York, 1989.

39. Domıngo LR, Pérez $P$, The nucleophilicity $N$ index in organic chemistry. Organic \& biomolecular chemistry, 2011;9.20: 7168-75.

40. Vela A, Gazquez JL, A relationship between the static dipole polarizability, the global softness, and the fukui function. Journal of the American Chemical Society, 1990; 112.4: 14902.

41. De Proft F, Amira F, Choho S, Geerlings P, Quantum-chemical study of the acidity of substituted acetic acids with density functional theory based descriptors. The Journal of Physical Chemistry, 1994; 98.20: 5227-33.

42. Tüzün B, Theoretical Evaluation of Six Indazole Derivatives as Corrosion Inhibitors Based on DFT, Turkish Comp Theo Chem (TC\&TC), 2018; 2(1): 12 - 22.

43. Üngördü $A$, Tezer N. The solvent (water) and metal effects on HOMO-LUMO gaps ofguanine base pair: a computational study, J. Mol. Graph. Model. 2017; 74: 265-72.

44. Üngördü A, Tezer N. DFT study on metalmediated uracil base pair complexes, J. Saudi
Chem. Soc. $2017 ; 21.7: 837-44$.

45. Erkan SK, Sayın K, Karakaş D. Theoretical Studies on Eight Oxovanadium(IV) Complexes with Salicylaldehyde and Aniline Ligands.

Hacettepe J. Biol. \& Chem. 2014; 42 (3): 33742.

46. Sychantha D, Jones CS, Little DJ, Moynihan $\mathrm{PJ}$, Robinson $\mathrm{H}$, Galley NF, Clarke AJ. In vitro characterization of the antivirulence target of Gram-positive pathogens, peptidoglycan Oacetyltransferase A (OatA). PLoS pathogens. 2017; 13(10):e1006667.

47. Aldape MJ, Tao A, Heeney DD, McIndoo ER, French JM, Xu D. Experimental identification and computational characterization of a novel extracellular metalloproteinase produced by Clostridium sordellii. RSC advances. 2017; 7(23): 13928-38.

48. Elavarasan T, Bhakiaraj DP, Gopalakrishnan M. Synthesis, spectral analysis, in vitro microbiological evaluation, and molecular docking studies of some novel 1 -(1-aryl-1Htetrazol-5-yl)-2-(piperidin-1-yl) ethanone derivatives. ISRN organic chemistry, 2014. 